\title{
The Morphosyntactic Properties in Angguruk Dialect of Yali Language
}

\author{
Simin Althur ${ }^{1}$, Djatmika ${ }^{2}$, Wiratno ${ }^{2}$ \\ ${ }^{1}$ Department of Linguistics, Sebelas Maret University, Surakarta, Indonesia \\ ${ }^{2}$ Department of English, Sebelas Maret University, Surakarta, Indonesia
}

Email address:

althurfamily@yahoo.com (S. Althur)

\section{To cite this article:}

Simin Althur, Djatmika, Wiratno. The Morphosyntactic Properties in Angguruk Dialect of Yali Language. International Journal of Language and Linguistics. Vol. 5, No. 1, 2017, pp. 6-14. doi: 10.11648/j.ijll.20170501.12

Received: August 24, 2015; Accepted: September 11, 2015; Published: February 13, 2017

\begin{abstract}
This research specifically studied the morphosyntactic property: verb formation process in Angguruk Dialect of Yali Language (thereafter called ADYL). ADYL is one out of 274 local languages in Papua and West-Papua Province. The speaker population of ADYL consists of 15000 persons. The method employed in this research was descriptive qualitative method. The technique of analyzing data used was syntactic basic operating technique called 'morphological merger' as logical demand of distributed morphology theory. From the result of analysis, a number of morphosyntactic properties were found supporting the creation of morphosyntactic verb. They were: (1) mood and its sub-classification; (2) aspect and its subclassification; (3) tense and its sub-classification; (4) the compatibility of subject to its sub-classification (subject agreement); (5) intensifier and its sub-classification; (6) object possessor markerandits sub-classification; (7) accusative object marker and its sub-classification, (8) causative verb marker; (9) reciprocal diathesis marker and its sub-classification, and (10) diathesis marker. All of those morphosyntactic properties have implication to the creation of morphosyntactic verb in ADYL.
\end{abstract}

Keywords: Morphosyntactic Property, Morphological Merger, Morphosyntactic Verb (Word)

\section{Introduction}

Angguruk dialect of Yali language ${ }^{1}$ (ADYL) becoming the object of current research is one out of 274 local languages existing in Papua Province (Foley, 1986: 3). Silzer (1991: 86) stated that this language's speaker population consists of over 15000 persons. In addition, this language belongs to non-Austronesia (NAN) language family. Exactly this language is called Papuan language, Trans-New Guineaphylum, Super-stock Sub-phylum-level, Dani-Kwerba Stock, Southern division, Dani big family, Ngalik-Nguda sub-family. This language is distributed throughout Angguruk sub district area, Yahukimo Regency ${ }^{2}$ of Papua Province. What attracts the author's attention is that ADYL has a very complex and unique morphosyntactic verb, formation process.

One representation of such the complexity and uniqueness is that ADYL has morphosyntactic properties

1 Called ADYL

2 Distribution area of Angguruk and Ninia dialects of Yali language constituting tense comprising: 1) present tense with unique morpheme ${ }^{3}$; 2) future tense divided into four sub categories: (i) first sub category of future tense (FUT1); (ii) second sub category of future tense (FUT2);(iii) third sub category of future tense (FUT3); (iv) fourth sub category of future tense (FUT4), and (iii) past tense divided into four sub categories as well: (i) first category of past tense (PAST1); (ii) second category of past tense (PAST2); (iii) third category of past tense (PAST3), and (iv) fourth category of past tense (PAST4). In addition, many peculiarities of morphosyntactic properties exist unlikely to be mentioned in piecemeal here.

The problems of research are: "What is morphosyntax, and what does it contain? These problems are considered as very important fundamental problems to pose, to build the morphosyntactic researches on obvious theoretic concept,

\footnotetext{
3 Unique, because its formation process is not prevalent, compared with morphemic process in Austronesia languages.
} 
rather than confusing and misinterpreted morphosyntax. See the representation of morphosyntactic concept applied so far by the researchers in Language Building and Development Center of Indonesia. See the figure below (morphosyntax version 1).

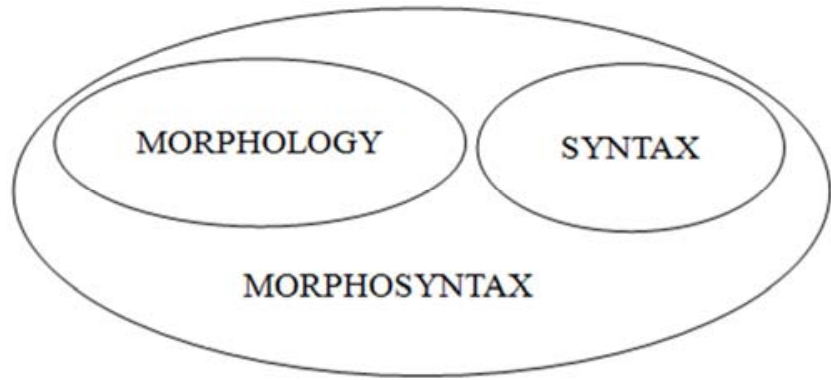

Figure 1. Language Building and Development Centre of Indonesia's Version of Morphosyntax.

The figure above reveals that 'morphology' and 'syntax' are both standing alone. In morphological study, some problems are discussed related to affixation, reduplication, pluralizing, actually constituting the content of morphological study. In syntax area, some points are discussed from phrase to discourse, but not related to morphological process. For that reason, the researches entitled morphosyntax so far are not feasible to be entitled so. They are only feasible to be entitled "morphology and syntax (X language).

This morphosyntactic research on ADYL is not like the previous morphosyntactic studies. This research keeps holding on the principle of morphosyntactic concept suggested by Katamba (1993: 14) and Radford (19975: 516). They assume that morphosyntax is a morphological process involving two linguistic levels: morphology and syntax. If morphosyntax is indeed a morphological process, there must be its word-form. The product of word-form is morphosyntactic word composed of morphosyntactic properties combined into root. In addition, such the process must require morphophonemic explanation because of the encounter of morphosyntatic property and root. Those two morphosyntactic versions do not touch the problem at all. For that reason, this research surely brings about morphosyntax different from previous version.

The morphosyntax intended still refers to the morphosyntactic concept as same as the version 2, but with different conception and application of concept, and different object (language) typology ${ }^{4}$. Although both of them refer to Katamba and Radford's morphosyntactic concept, this research's findings are certainly different from the previous ones'. The difference can be seen from the figure below, and compare it with figure 1 above.

\footnotetext{
${ }^{4}$ Non-Austronesia language object, exactly Papuan phylum
}

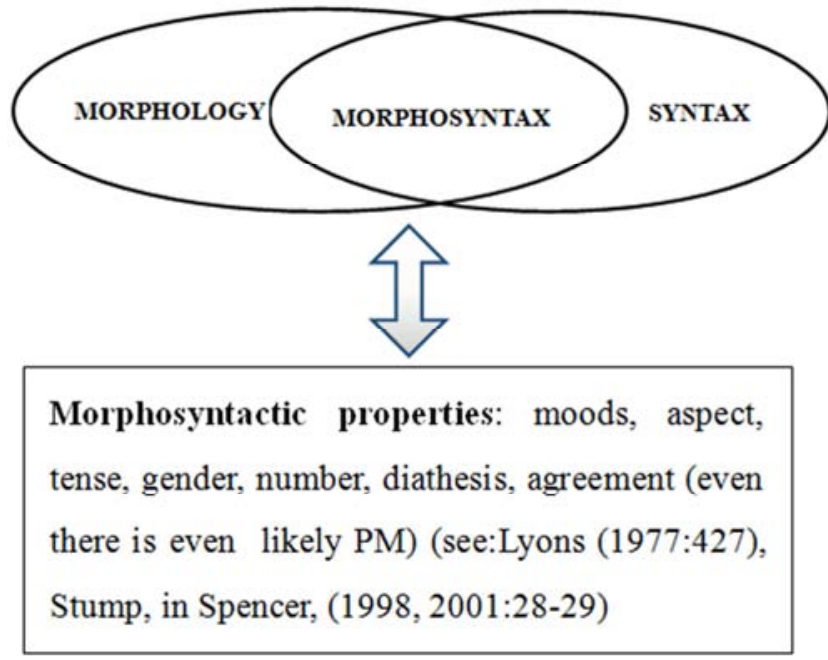

Figure 2. Is a picture of morphosyntax developed in this study.

Considering such the big question, the problem of research is limited to how to solve the problems related to morphosyntactic property constituting the 'essence' of morphosyntax. Regarding such the 'essence', this study is a research examining the 'essence (content)' of ADYL's morphosyntax, including: (i) whether there are morphosyntactic categories or types (mood, aspect, tense, agreement, number, gender, diathesis (active, passive, reciprocal, and etc)) in ADYL (on the basis of verb); (ii) how the process of creating ADYL's morphosyntactic verb is with those properties, and (iii) what the structure pattern of ADYL's morphosyntactic verb is.

Thus, the objective of research was to answer the questions above comprehensively, based on data and fact of ADYL, supported by the sufficiently sophisticated linguistic theory, Distributed Morphology (Hale and Maratz, 1993). This theory is considered as very compatible to the typology of ADYL's morphosyntactic.

\section{Research Method}

\subsection{Type of Research}

This study could be generally called a descriptive qualitative research (see Soetopo, 2006: 40). The term of qualitative research tended to be used in contrast to that of quantitative research.

Viewed from the final objective of research, this study belonged to basic research rather than applied research. Meanwhile, viewed from the setting, this study was a field research.

\subsection{Location of Research}

Yali language (Angguruk dialect) becoming the object of research consisted of three dialects: Angguruk, Ninia, and Pass Valley. The distribution areas of individual dialects were: Angguruk District for Angguruk dialect; Ninia District for Ninia dialect, and Kurima District for Pass Valley dialect, Yahukimo Regency, and some part of Mapenduma District 
area, Jayawijaya Regency.

\section{MAP OF YAHUKIMO REGENCY}

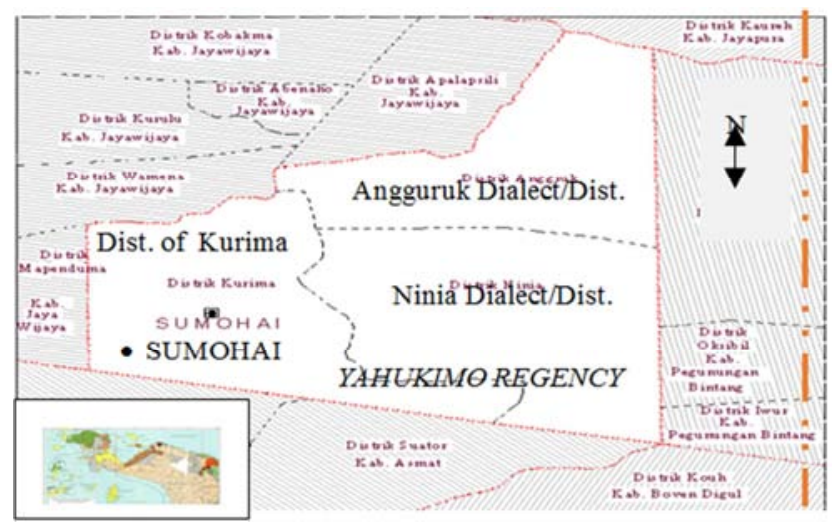

Legend:

- City of Yahukimo Regency

......... Border of Yahukimo Regency

— $\cdots$ B Border of Indonesia \& PNG

\subsection{Data and Data Source}

The data of research consisted of primary and secondary ones. Primary data constituted the spoken corpus deriving from informant, and the secondary one constituted the written corpus deriving from script or text commonly written by SIL researcher. These primary and secondary data were determined based on basic assumption that essentially language is utterance or speech, while writing is only transcription of speech. The script or text was defined as the secondary data based on fact that culturally Yali tribe was unfamiliar with written culture like Javanese, Batak, Bugis, Makassar and other tribes in Indonesia. That was why the scripts in Yali language (generally) and (particularly) ADYL were very limited. Regarding the informant as primary data source, Samarin (1998: 52) added that when a research pertains to the determination of a language's structure outline, more than one good informant is usually unnecessary (according to the author's rating). It implies that some informants are good and some others are less good (giving information smartly or less smartly). Furthermore, it confirms that the type of study requires many informant dialectology and sociolinguistic studies. Thus, this research might use 1 to 5 informants, dependent on the field condition, by keeping considering the following requirements of informant: (i) must be native speakers; (ii) healthy physically and mentally; (iii) no auditory disability; (iv) can speak Indonesian; (v) have never wander about in long time; (vi) still use ADYL actively; (vii) have adequate knowledge on their community language, culture and custom, and (viii) not too old and not too young adults.

\subsection{Technique of Analyzing Data}

The identification of morpheme characteristic referred to the procedures introduced by Elson and Pickett (1969: 18), but morphosyntactic verb analysis employed the

morphosyntactic-operation technique suggested by Cash Cash (2004: 1) ${ }^{5}$ as follows. Firstly, examining morphosyntactic word by its components consisting of four main representations: (i) the surface form, (ii) the morphological form, (iii) the morphological gloss, and (iv) the free translation.

Each of those elements was organized in interlinear form, as illustrated in the example ${ }^{6}$ below.

(1) Morphological Representation in Interlinear Form

The surface form

The morphological form

The morphological gloss

The free translation

\author{
hiwlé keřyke \\ hi- wilé-keřéy -ke \\ 3NOM-run-move/change. \\ location. or. position -PAS \\ 'He/she/it ran.'
}

Secondly, providing assessment foundation to the words examined from each lexical morpheme entry, including the root verb. Speaking about lexical entry, we only refer to mental dictionary speakers existing in their mind and for the linguistic content relationship as the attribute the human beings use. For example, when we study the morphological elements in /hiwlékeřyke/ 'he/she/it ran', we follow the lexical entry as illustrated in the example (2) below.

(2) /hi-/Phonological Representation

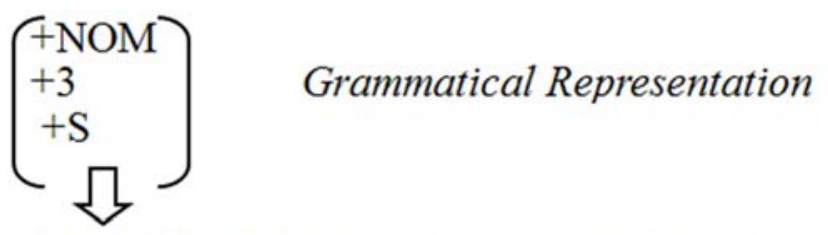

\section{$\lceil\mathrm{HE} / \mathrm{SHE} / \mathrm{IT} \mathrm{RAN}\rceil$ Semantic Representation}

In the example (2) above, /hi/ is a string of phonemes and subsequently called phonological representation. Grammatical representation consists of a set categorized into nominative grammatical feature [ $+\mathrm{NOM},(\mathrm{PRON})+3 \mathrm{~s}]$ contributing to morpheme identity. It means that nominative category differentiates this morpheme as 'subject' and has quality value for (third) person and (singular) number. Similarly, semantic representation shows conceptual content or meaning of the morpheme. The important linguistic fact here is that the three representations are activated when the speaker chooses lexical entry from its mental dictionary and put it into human language.

When we observe an individual's utterance grammatically, like in the previous example (1), we know that morphosyntactic operation is working taking into account all properties of lexical entry and morphosyntactic corresponding to the environment it enters into. We know that such the operation is the syntactic one because it assembles various morphemes into a larger coherent structure, for example (verbal phrase, nominal phrase, etc). To explain this phenomenon, this study adopted linguistic theory called "Distributed Morphology (DM)" (Halle and Marantz, 1993). This theory asserts that morpheme is an

5 In his writing "Nez Perce Verb Morphology”. University of Arizona, 2004.

6 Cash Cash, loc. cit. 
'atom' of morphosyntactic representation and an operation assembling the morpheme into a motivated coherent structure in an idea that morphemes combine directly from their grammatical representation, as illustrated in the example (2).

In the concept of data analysis, the root verb is represented (see the example 1) in the attempt of sub-categorization developing into lexical word entry concept. The frame of sub-categorization determines the local tempt of a vocabulary item chosen and then included through morphological merger.

(3)

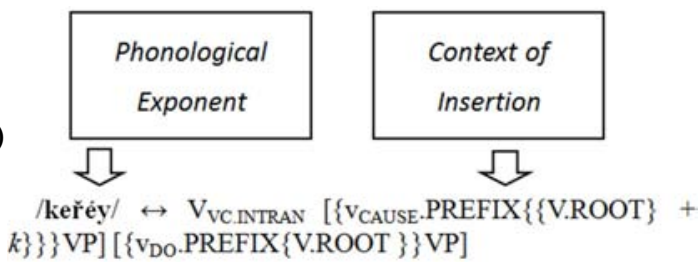

The frame of sub categorization in (3) provides a number of facts about the structure of root-verb / keréy $\mathrm{v}_{\mathrm{vd}}$. Firstly, identifying intransitive verb notation $\left(\mathrm{V}_{\mathrm{C} \cdot \text { INTRAN }}\right)$ and as the classification of $\mathrm{V}_{\mathrm{C}}$. Secondly, as $\mathrm{V}_{\mathrm{C}} / \mathrm{keré}$ / $/$ has option of choosing one out of two potential insertion points, each of which has its own categorical composition. Here it can be seen that the insertion context can be seen as characterized by outer bracket $[\ldots]$ while inner bracket $\{\ldots\}_{\mathrm{VP}}$ identifies successive morphemes, in this case, verb phrase domain. Thirdly, /keřé $\mathrm{v}_{\mathrm{VC}} /$ is a dependent root-verb and takes obligatory verbal prefix consisting of two types: $\mathrm{V}_{\mathrm{CAUSE}}$ and $\mathrm{V}_{\text {DO }}$. Consider thoroughly the example (3), we can see that when / keřé $\mathrm{v}_{\mathrm{vC}} /$ has an option to choose $[+\mathrm{k}]$ as a verbal suffix element, it should also choose $\mathrm{V}_{\mathrm{CAUSE}}$, or when suffix [-k] is not chosen (meaning that it has minus [-] value), /keré $\mathrm{y}_{\mathrm{VC}} /$ belongs to the same category as $\mathrm{V}_{\mathrm{DO}}$. In addition to the potential combination of verb and verbal affix, the phonological component is sufficiently productive at morphological level of verb. When the phonological elements of root verb or verbal affix are added with phonological exponents of basic form, it will be represented onto surface allomorphemically, as described below.

(4) /wileV.CAUSE/ $\rightarrow$ /wlé/ 'run, move quickly'

\section{/keřéyVC/ $\rightarrow /$ keřy/ 'move/change location'}

The advantage of sub-categorization frame is that it also enables us to examine how a verb phrase is assembled as the component of morphosyntactic word. Just like all verbs, $/$ keř́é $\mathrm{vd}_{\mathrm{v}}$ needs subject and time expression. To show this fact, the verb list is made; the followings are the verb phrases occurring in a list larger than the morphosyntactic word themselves: $\{\ldots,\{\ldots\} \mathrm{vP}, \ldots\}_{\mathrm{MW}}$. So, the example (5) below indicates the formed morphosyntactic (from example (1)).

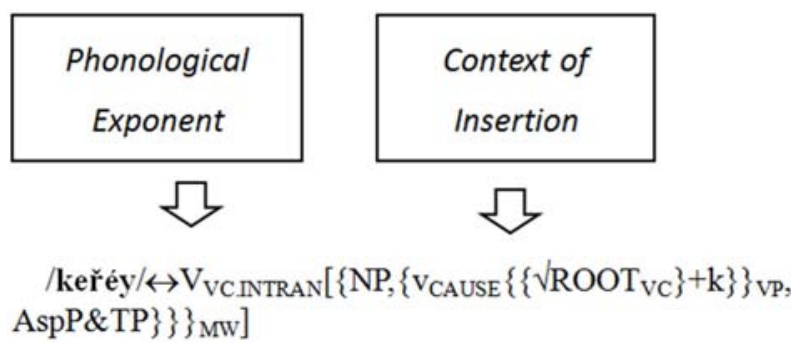

/hiwlé·keřyke/

hi- wilé-keřéy -ke

3 NOM- run- change location -PST

'He/she/it ran.'

Into morphosyntactic word hiwile (example 5) the noun phrase (FN) $\{h i-\}$ is included as subject. In addition, there are verb phrase (VP), aspect phrase (AF), and tense phrase (TF) the event time of which is represented by verb. The composition of verb phrase enables to interpret the subject from /hiwlé'keryke/ 'He/she/it ran' as the PROTO-PATIENT of subject.

\section{Result and Discussion}

\subsection{Result}

Considering the result of analysis, it could be found a number of morphosyntactic properties building the structure of morphosyntactic verb in ADYL, with morphosyntactic property sub categories as shown in the following table.

Table 1. Sub-classification of Morphosyntactic Property: Mood.

\begin{tabular}{lllll}
\hline SUBJ & Type of Mood & Morpheme Marker & Morpho-syntactic Word & Gloss \\
\hline- & Honorific & $\{-\mathrm{r}(\mathrm{V})-\}$ & haharuk & (is) writing \\
- & Non-honorific & $\{-\mathrm{t}(\mathrm{V})-\}$ & hahatuk & (is) writing \\
$1,2,3 \mathrm{~s}$ & Desiderative & $\{-\mathrm{le}\}$ & nele & wants to eat \\
$1,2,3 \mathrm{pl}$ & Desiderative & $\{-\mathrm{il}-\}$ & nila & wants to eat \\
$2 \mathrm{t} / 2 \mathrm{pl}$ & Interrogative & $\{-\mathrm{n}\}$ & nelen & eat? \\
$2 \mathrm{~s}$ & Imperative & $\{-\mathrm{in}\}$ & habulin & dig! \\
$2 \mathrm{pl}$ & Imperative & $\{-\mathrm{ihib}\}$ & habulihib & dig! \\
\hline
\end{tabular}

Table 2. Sub-classification of Morphosyntactic Property: Aspect.

\begin{tabular}{lllll}
\hline SUBJ & Type of Aspect & Aspect Marker & Morphosyntactic Word & Gloss \\
\hline \multirow{2}{*}{$1,2,3 \mathrm{~s} / \mathrm{pl}$} & Desiderative (DUR) & $\{$-uk $\}$ & haharuk & is sending \\
& Frequentative (Fre) & $\{$-DUP & nohoruk-nohoruk & sleeping continuously \\
\hline
\end{tabular}


Table 3. Present Tense.

\begin{tabular}{|c|c|c|c|c|c|c|}
\hline \multirow{2}{*}{ SUBJ } & \multicolumn{6}{|c|}{ PRESENT TENSE AND ITS AGREEMENT TO SUBJECT } \\
\hline & ROOT & DUR & Present & Subject Agreement & Morphosyntactic Word & Gloss \\
\hline $1 \mathrm{~s}$ & & & & $\{-\mathrm{i}\}$ & naruklahi & 'I am eating' \\
\hline $1 \mathrm{pl}$ & & & & $\{-\mathrm{e}\}$ & naruklahe & 'we are eating' \\
\hline $2 \mathrm{~s}$ & $\sqrt{n} a$ & $\{-\nu k t$ & (-loh) & $\{-\mathrm{en}\}$ & naruklahen & 'you are eating' \\
\hline $2 \mathrm{pl}$ & vna & $\{-u \kappa\}$ & $\{-\tan \}$ & $\{-\mathrm{eb}\}$ & naruklaheb & 'you are all eating' \\
\hline $3 \mathrm{~s}$ & & & & $\{-a\}$ & naruklaha & 'he is eating' \\
\hline $3 \mathrm{pl}$ & & & & $\{-\operatorname{ken}\}$ & narukken & 'they are eating' \\
\hline
\end{tabular}

Table 4. Future Tense (FT).

\begin{tabular}{|c|c|c|c|c|}
\hline \multirow{2}{*}{ SUBJ } & \multicolumn{4}{|c|}{ FUTURE TENSE AND ITS AGREEMENT TO SUBJECT } \\
\hline & Future-1 (FUT $\left.{ }_{1}\right)$ & Futute-2 (FUT $\left.{ }_{2}\right)$ & Future-3 (FUT $\left.{ }_{3}\right)$ & Future-4 (FUT 4 ) \\
\hline $1 \mathrm{~s}$ & $\{-\min \}$ & $\{$-huk\} & $\{$-huken\} & $\{$-hukon $\}$ \\
\hline $1 \mathrm{pl}$ & $\{-\mathrm{ul}\}$ & $\{$-huk $\}$ & $\{$-huken $\}$ & $\{$-hukon\} \\
\hline $2 \mathrm{~s}$ & $\{-\operatorname{mihin}\}$ & $\{$-hun $\}$ & $\{$-hunen $\}$ & $\{$-hunon $\}$ \\
\hline $2 \mathrm{pl}$ & $\{-h i b\}$ & $\{-$ hub $\}$ & $\{$-huben $\}$ & $\{$-hubon $\}$ \\
\hline $3 \mathrm{~s}$ & $\{$-misi $\}$ & $\{-h u\}$ & $\{$-huen $\}$ & $\{$-huon $\}$ \\
\hline $3 \mathrm{pl}$ & $\{$-usa $\}$ & $\{-$ hub $\}$ & $\{$-huben $\}$ & $\{$-hubon $\}$ \\
\hline
\end{tabular}

Table 5. Past Tense (PT).

\begin{tabular}{|c|c|c|c|c|}
\hline \multirow{2}{*}{ SUBJ } & \multicolumn{4}{|c|}{ PAST TENSE AND ITS AGREEMENT TO SUBJECT } \\
\hline & PAST $_{1}$ & PAST $_{2}$ & PAST $_{3}$ & $\begin{array}{l}\text { PAST }_{4} \\
\end{array}$ \\
\hline $1 \mathrm{~s}$ & & \{-huken\} & $\{-$ kiak $\}$ & $\{$-kiahon $\}$ \\
\hline $1 \mathrm{pl}$ & & $\{$-huken\} & $\{-$ kuak $\}$ & $\{-$ kuahon $\}$ \\
\hline $2 \mathrm{~s}$ & & $\{$-hunen\} & $\{-$ kinak $\}$ & $\{$-kinahon $\}$ \\
\hline $2 \mathrm{pl}$ & $\{-1 h\}$ & $\{$-huben $\}$ & $\{$-kibak\} & $\{$-kibahon $\}$ \\
\hline $3 \mathrm{~s}$ & & $\{$-huen\} & $\{$-siak $\}$ & $\{$-siahon $\}$ \\
\hline $3 \mathrm{pl}$ & & $\{$-huben $\}$ & $\{-$ kuak $\}$ & $\{$-kuahon $\}$ \\
\hline
\end{tabular}

Table 6. Object Possesor Marker.

\begin{tabular}{|c|c|c|c|}
\hline Pron: OP & OP Marker & Example of clause/sentence & Gloss \\
\hline $1 \mathrm{~s}$ & $\{-$ nap $\}$ & a(t)renhalihengnaptuk & 'he/she asks for (my) banana' \\
\hline $1 \mathrm{pl}$ & $\{-$ nenep $\}$ & $\mathrm{a}(\mathrm{t}) \mathrm{renhalihengneneptuk}$ & 'he/she asks for (our) banana' \\
\hline $2 s$ & $\{$-hap $\}$ & antenhomhenghabihi & 'I asked for your taro' \\
\hline $2 \mathrm{pl}$ & $\{$-henep & antenhalihengheneptuk & 'I ask for your banana' \\
\hline $3 \mathrm{~s}$ & $\{-\mathrm{ap}\}$ & antenhomhengaptuk & 'I ask for the taro' \\
\hline $3 \mathrm{pl}$ & $\{$-enep $\}$ & antenhomhengeneptuk & 'I ask for their taro' \\
\hline
\end{tabular}

Table 7. Object Accusative Marker.

\begin{tabular}{llll}
\hline Pron: OA & OA Marker & Sample clause/sentence & Gloss \\
\hline $1 \mathrm{~s}$ & $\{-\mathrm{na}\}$ & $\mathrm{a}(\mathrm{t})$ renyetnasug & 'he/she waits for me' \\
$1 \mathrm{pl}$ & $\{-\mathrm{nene}\}$ & $\mathrm{a}(\mathrm{t})$ renyetnenesug & 'he/she waits for us' \\
$2 \mathrm{~s}$ & $\{-\mathrm{hene}\}$ & $\mathrm{a}(\mathrm{t})$ renyethenesug & 'he/she waits for you' \\
$2 \mathrm{pl}$ & $\{-\mathrm{hene}\}$ & $\mathrm{a}(\mathrm{t})$ renyethenesug & 'he/she waits for you all' \\
$3 \mathrm{~s}$ & $\{-\mathrm{a}\}$ & antenyetasug & 'I wait for him' \\
$3 \mathrm{pl}$ & $\{-\mathrm{ene}\}$ & antenyetenesug & 'I wait for them' \\
\hline
\end{tabular}

Table 8. Morpheme Intensifier.

\begin{tabular}{|c|c|c|c|c|c|c|}
\hline \multicolumn{2}{|c|}{$\begin{array}{l}\text { Future Tense } \\
\text { Intensifier }\end{array}$} & \multicolumn{2}{|c|}{$\begin{array}{l}\text { Past Tense } \\
\text { Intensifier }\end{array}$} & \multirow[t]{2}{*}{ Sample clause/sentence } & \multirow[t]{2}{*}{ gloss } & \multirow[t]{2}{*}{ Note } \\
\hline FUT $_{1}$ & FUT $_{2}$ & PAST $_{1}$ & PAST $_{2}$ & & & \\
\hline$\{-\mathrm{en}\}$ & $\{$-on $\}$ & $\{-\mathrm{ak}\}$ & $\{-$ on $\}$ & $\begin{array}{l}\mathrm{i}(\mathrm{t}) \text { ren e haruhuben } \\
\mathrm{i}(\mathrm{t}) \mathrm{ren} \text { e haruhubon } \\
\mathrm{i}(\mathrm{t}) \mathrm{ren} \text { e harukubak } \\
\mathrm{i}(\mathrm{t}) \text { ren e harukubahon }\end{array}$ & $\begin{array}{l}\text { 'they will carry wood on their shoulders' } \\
\text { 'they will carry wood on their shoulders' } \\
\text { 'they have carried wood on their shoulders' } \\
\text { 'they have carried wood on their shoulder's }\end{array}$ & $\begin{array}{l}\text { still occurring in a long time } \\
\text { very long time } \\
\text { has been long time } \\
\text { very long time }\end{array}$ \\
\hline
\end{tabular}

Table 9. Reciprocal Diathesis.

\begin{tabular}{llll}
\hline Reciprocal Type & Example & gloss & Note \\
\hline Balanced reciprocity & It yikhalok-halok & 'they are in quarrel' & No one lost \\
Unbalanced reciprocity & It yikhalik-halok & 'they are in quarrel' & Someone is lost \\
\hline
\end{tabular}


Table 10. Negation Marker.

\begin{tabular}{lll}
\hline Negation Marker & Sample clause/sentence & gloss \\
\hline$\{$-fug $\}$ & At suburunamisifug & 'he/she does not like eating potatos' \\
\hline
\end{tabular}

Table 11. Subject Agreement1.

\begin{tabular}{llll}
\hline SUBJ & Subject Agreement & Morphosyntactic Verb & Gloss \\
\hline $1 \mathrm{~s}$ & $\{-\mathrm{i}\}$ & naruklahi & 'I am eating' \\
$1 \mathrm{pl}$ & $\{-\mathrm{e}\}$ & naruklahe & 'we are eating' \\
$2 \mathrm{~s}$ & $\{-\mathrm{en}\}$ & naruklahen & 'you are eating' \\
$2 \mathrm{pl}$ & $\{-\mathrm{eb}\}$ & naruklaheb & 'you are all eating' \\
$3 \mathrm{~s}$ & $\{-\mathrm{a}\}$ & naruklaha & 'he is eating' \\
$3 \mathrm{pl}$ & $\{-\mathrm{ken}\}$ & narukken & 'they are eating' \\
\hline
\end{tabular}

\subsection{Discussion}

Referring to the concept of analysis suggested by Distributed Morphology through Cash Cash, it can be concluded that ADYL still has a number of very complicated morphosyntactic properties ${ }^{7}$. However, as we are dependent on administrative limitation ${ }^{8}$, this paper only presents a little of research findings considered as interesting to present in this forum.

\subsection{Tense (T)}

Hartmann \& Stork (1973: 235) stated that tense is a grammatical category of verb and expresses it in contrast to the grammatical relationship of time to action, as intended in the sentence and expression time. Furthermore it is explained that traditional grammar differentiates tense into three basic forms: past, present, and future. ADYL has all of those categories, but here future and past tenses are subdivided into several sub categories ${ }^{9}$. The discussion section in this paper is only limited by morphosyntactic property constituting tense. The limitation is made because of the following reasons: (i) the property is very interesting, (ii) the structure of morphosyntactic verb (MV) with tense marker is very complex; likely containing mood, aspect, tense (it self), and agreement. The subject matter of current article focuses specifically on present, past, and future tense with the first singular personal pronoun as the subject.

i. Morphosyntactic-Verb with Present Tense Marker $\{$-lah\}

Inflective category constituting the morphosyntactic property of present tense (PT) in ADYL is identified morphologically by $\{-l a h\}$. The form $\{-l a h\}$ is a dependent morpheme, but syntactically $\{-l a h\}$ is also a syntactic component, because grammatically it serves as tense marker, and tense is one of morphosyntactic properties (see: Lyons, 1997: 427). It is in line with Katamba (1993: 14) and Radford (1997: 516) stating that morphologic process associates two linguistic levels: morphology and syntax. The result of two linguistic level combination generates term morphosyntax later. That combination process is called morphological merger in Distributed Morphology Theory. To explain further morphosyntactic verb (MV) formation process with present tense (PT) marker, consider first the data of morphological representation ${ }^{10}$ in interlinear form ${ }^{11}$. Consider also the morphosyntactic verb in italic in the morphological form in clause/sentence (1) a-f) below.

(1)

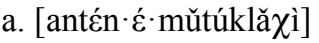

$$
\begin{aligned}
& \begin{array}{ccc}
\text { ant - en } & \text { e } & m u t-u k-l a h-i \\
\text { 1s - TS } & \text { tree } & \text { cut - DUR - PRES - S: 1s } \\
\hline \mathrm{S} & \mathrm{O} & \mathrm{V}
\end{array}
\end{aligned}
$$

$\mathrm{TS}=$ transitive subject

'I am cutting the wood'

b. [nirén $\cdot \dot{\varepsilon} \cdot$ mǔtúklă $\chi \dot{\varepsilon}]$

$$
\begin{array}{ccc}
\text { ni(t)r - en } & \text { e } & \text { mut }-u k-l a h-e \\
1 \mathrm{pl}-\mathrm{TS} & \text { tree } & \mathrm{cut}-\mathrm{DUR}-\mathrm{PRES}-\mathrm{S}: 1 \mathrm{pl} / \mathrm{IN} \\
\hline \mathrm{S} & \mathrm{O} & \mathrm{V}
\end{array}
$$

'We are cutting the wood'

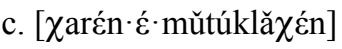

$$
\begin{aligned}
& \mathrm{ha}(\mathrm{t}) \mathrm{r} \text { - en e mut - uk - lah - en } \\
& \begin{array}{ccc}
2 s-T S & \text { wood } & \text { cut }- \text { DUR - PRES - S: 2s/INT } \\
\hline S & 0 & V
\end{array}
\end{aligned}
$$

'you are cutting the wood'

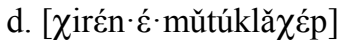

$$
\begin{array}{ccc}
\text { hi }(\mathrm{t}) \mathrm{r}-\mathrm{en} & \mathrm{e} & m u t-u k-l a h-e b \\
\text { 2pl-TS } & \text { wood } & \text { cut - DUR - PRES - S: 2pl/INTER } \\
\hline \mathrm{S} & \mathrm{O} & \mathrm{V}
\end{array}
$$

'you are all cutting the wood'

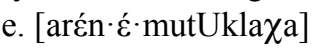

$$
\begin{array}{ccc}
\text { a(t)r-en } & \text { e } & \text { mut }-u k-l a h-a \\
\text { 3s-TS } & \text { wood } & \text { cut - DUR - PRES - S: 3s } \\
\hline \mathrm{S} & \mathrm{O} & \mathrm{V}
\end{array}
$$

'he/she is cutting the wood'

\footnotetext{
7See subclassification items 1 and so on, elaboration of research result (3.1). 8 SeeBukuPanduanPenulisanDisertasi, First Edition 2013.

9 See the explanation (1) in introduction section p.1.
}

10 (Data) consisting of four lines: (i) surface form; (ii) morphological form; (iii) morphological gloss), and (iv) free translation.

11 The terms are adopted from Cash Cash (2004)in Nez Perce Verb Morphology 


$$
\begin{aligned}
& \text { f. [irén·éc mutÚk:én] } \\
& \mathrm{i}(\mathrm{t}) \mathrm{r}-\mathrm{en} \text { e mut - uk - } \varnothing-k e n \\
& \begin{array}{ccc}
3 \mathrm{pl}-\mathrm{TS} & \text { wood } & \text { cut }- \text { DUR }- \text { PRES }-\mathrm{S}: 3 \mathrm{pl} \\
\hline \mathrm{S} & 0 & \mathrm{~V}
\end{array}
\end{aligned}
$$

'they are cutting the wood'

The morphosyntatic verbs in clause (1) a-f)) above are all built on pre-categorical root $\sqrt{m u t}$ 'cut', coupled with morphosyntactic property with durative aspect marker (DUR) $\{-u k\}$ first and then becoming/mutuk/. After the morphosyntactic verb/mutuk/ is formed, tense marker and subject marker (cross reference) can join /mutuk/ concurrently. In other word, tense and subject markers cannot join MV/mutuk/ independently. Meanwhile semantically \{lah \} contains grammatical meaning (notion) 'work, action being done' corresponding to the verb to which it attaches.

From the data above, one form of root is taken with different subject filling personal pronoun. It is intended to check whether or not the different filling subject pronouns affect the change of present tense marker form $\{-l a h\}$. In fact, there is no change in sentences (1) a-e)), but there is a change in (f) with the third plural personal pronoun subject (3j) in which there is tense marker (Ø) deletion. Even there is no change in durative aspect marker (DUR) $\{-u k\}$, while the subject marker changes with personal pronoun filling in the subject. Then, to confirm the elaboration, it can be seen the morphosyntactic verb (MV) formation process sequence represented schematically in the figure below.

$$
[\mathrm{mut}] \leftrightarrow\left[V_{t-\operatorname{tra}}\left\{\sqrt{v_{t}}\right\}+\{-u k\}+\{-l a h\}\left(\begin{array}{c}
-i \\
-e \\
-e n \\
-e b \\
-a \\
\text { Expnont }
\end{array}\right) M V\right]
$$

From the figure above, it can be seen the morphosyntaticverb formation process existing in the phonological exponent column. The MV is made of root-verb-action subcategory and then attached with durative aspect marker $\{-\mathrm{uk}\}$, but it cannot attach on its own, because it should attach concurrently with non-honorific mood $\{-\mathrm{t}-\}$ positioned on its left. Then, the present tense marker $\{-l a h\}$ is put along with the subject marker (cross-reference) $\{-\mathrm{i} /-\mathrm{e} /-\mathrm{en} /-\mathrm{ep} /-\mathrm{a} /-\mathrm{ken}\}$. Considering the scheme of MV formation process, the structure (str.) of morphosyntactic verb is represented below.

$$
\text { Str. MV }=\sqrt{ }+\text { Asp:DUR }+[(\text { PERS) }(\text { S.Agr. })]
$$

In addition, when morphosyntatic verb (MV) is analyzed from syntactic aspect, it can be said that it (MV) is categorized into verb phrase (VP). In such the verb phrase, there are a non-honorific mood, a durative aspect (DUR), a present tense (PT) marker, and subject agreement.

ii. Morphosyntactic-Verb: with First Sub Category of Future Tense (FUT1) marker and the First Singular Person Subject $\{-$ min\}

Inflective category constituting the morphosyntactic property of first sub category of future tense $\left(\mathrm{FUT}_{1}\right)$ with the first singularperson subject /an/ 'I', in ADYL is marked morphologically with inflectional complex affix $\{-\min \}$. For further explanation on the process of creating morphosyntatic verb (MV) with first sub category of future tense $\left(\mathrm{FUT}_{1}\right)$ and the first singular person subject, consider first the morphological representation data in interlinear form. Consider also the morphological verb in italic in morphological form in the following clauses/sentences.

(2) a. [antén $\cdot \dot{\varepsilon} \cdot$ mutmín]

$$
\begin{array}{ccc}
\text { ant - en } & \text { e } & \text { mut - min } \\
\text { 1s - TS } & \text { wood, tree } & \text { cut }-\mathrm{FUT}_{1} / \mathrm{S}: 1 \mathrm{~s} \\
\hline \mathrm{S} & \mathrm{O} & \mathrm{V}
\end{array}
$$

'I will cut wood for a while'

b. [antén· su ${ }^{\mathrm{w}} \dot{\varepsilon} \operatorname{singá} \cdot \chi a \chi$ atimín]

ant - en suesingga haha - $t i \quad$ - $\min$

$$
\begin{array}{ccc}
\text { 1s }- \text { TS } & \text { letter } & \text { write }-\mathrm{NHn}-\mathrm{FUT}_{1} / \mathrm{S}: 1 \mathrm{~s} \\
\hline \mathrm{S} & \mathrm{O} & \mathrm{V}
\end{array}
$$

'I will write a letter for a while'

c. [antén·sum·ta ántimìn]

$$
\begin{aligned}
& \text { ant }- \text { en sak } \operatorname{tahan}(t)-t i \quad-\min \\
& \begin{array}{ccc}
\text { 1s }-\mathrm{TS} & \text { red }- \text { fruit } & \text { pick }-\mathrm{NHn}-\mathrm{FUT}_{1} / \mathrm{S}: 1 \mathrm{~s} \\
\hline \mathrm{S} & 0 & \mathrm{~V}
\end{array}
\end{aligned}
$$

'I will pick red fruit for a while'

d. [antén $\cdot \varepsilon ́ \cdot$ lisirimín]

$$
\begin{array}{ccc}
\text { ant - en } & \text { e } & \text { lisi }(k)-r i-\min \\
\text { 1s - TS } & \text { wood } & \text { pull }-\mathrm{Hn}-\mathrm{FUT}_{1} / \mathrm{S}: 1 \mathrm{~s} \\
\hline \mathrm{S} & \mathrm{O} & \mathrm{V}
\end{array}
$$

'I will pull the wood for a while'

$$
\text { e. [antén } \cdot \dot{\varepsilon} \cdot \chi \text { aririmín] }
$$

$$
\begin{array}{ccc}
\text { an - en } & \text { e } & \text { hari(uk) }-r i-\min \\
1 \mathrm{~s}-\mathrm{TS} & \text { wood, tree } & \text { carry on }-\mathrm{Hn}-\mathrm{FUT}_{1} / \mathrm{S}: 1 \mathrm{~s} \\
\hline \mathrm{S} & \mathrm{O} & \mathrm{V}
\end{array}
$$

'I will carry on the wood for a while'

The morphosyntactic verbs in clauses $(2$ (a-e)) are built on pre-categorical root $\sqrt{m u t}$ 'cut', and categorical verbs $\sqrt{\text { hahat }}$ 'write', $\sqrt{\text { tahant }}$ 'pick'; $\sqrt{\text { lisik }}$ 'pull' and $\sqrt{\text { haruk }}$ 'carry on'. The roots are then attached with FUT $_{1}$ marker $\{-\min \}$ inclusive into the first singular person subject but cannot be disentangled or segmented into distinctive form. Nevertheless, Distributed Morphology theory offers a method called vocabulary item $(\mathrm{VI})^{12}$. With the vocabulary

12 See:Noyer (1997)Features, Positions and Affixes in Autonomous Morphological Structure. 
item, the forms like $\{-\min \}$ can be disentangled: $\{-\min \} \leftrightarrow$ [FUT 1 ] [AGENT] [1s]. It means that $\{-\min \}$ serves as the marker of $\mathrm{FUT}_{1}$, in which there is subject marker or the first singular personal pronoun (1s). Meanwhile, semantically, \{$\min \}$ contains grammatical meaning (notion) 'the work to be done for a while, or soon by the first singular person', corresponding to the root to which it attaches.

Considering the data above, it can be found that in the morphosyntactic verb (MV) formation process with $\mathrm{FUT}_{1}$ marker $\{-\min \}$, allomorphemic change occurs, but no change occurs in $\mathrm{FUT}_{1}$ marker morpheme and there is a change in the root to which it attaches to. It is a very interesting phenomenon to study further. Consider each of roots $\sqrt{\text { mut }}$ (2a); $\sqrt{\text { haha }}(2 \mathrm{~b}) ; \sqrt{\text { tahant }}(2 \mathrm{c}) ; \sqrt{\text { lisi }}$ (2d), and $\sqrt{\text { haruk }}$ (2e). There is no allomorphemic change occurring in roof (2a-c) either in root or in morpheme marker. Even replacing process occurs in $\sqrt{\text { lisi }} k(2 \mathrm{~d})$ between $[k]$ and $[r]$ leading $\sqrt{\text { lisi }} k$ to change into $\sqrt{\text { lisir }}$, while no change occurring in the morpheme of tense marker attaching to the root. Allomorphemic change occurs in $\sqrt{\text { haruk }}$ (2e) root in coda constituting the melted sound obstructive velar consonant $[k]$ and sonority formerly constituting upper round back vocal $[\mathrm{u}]$ replaced with upper not-round front vocal $[i]$, so that $\sqrt{\text { haruk }}$ changes into $\sqrt{\operatorname{hari(k)}}$, as it is attached with $\mathrm{FUT}_{1}$ marker morpheme $\{-\min \}$ with first singular person subject, while /-r-/ occurs as the result of listeners ${ }^{13}$. It is a scarce and very interesting allomorphemic process phenomenon. The morphosyntatic verb (MV) formation can be seen in the chart of process below.

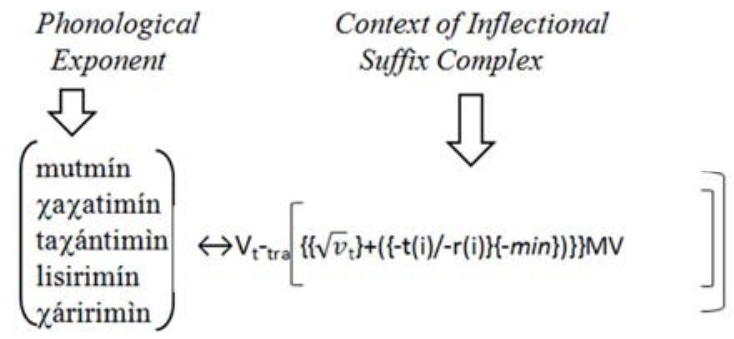

From the figure above, it can be seen the morphosyntactic verb (MV) formation process existing in phonological exponent column. The MV is composed of root-verb-action $\left(\sqrt{v}_{\mathrm{t}}\right)$ sub category, and then attached with $\mathrm{FUT}_{1}$ marker $\{-$ $\min \}$, along with honorific $(\mathrm{Hn})$ or non-honorific $(\mathrm{NHn})$ mood markers on the left, and inclusive into subject agreement with the first singular personal pronoun (1st).

Str. MV-FUT $1=\sqrt{ }+$ MOD:Hn/NHn $+\left[\left(\mathrm{FUT}_{1}\right)(\mathrm{S} . \mathrm{Agr}: 1 \mathrm{~s})\right]$

From the analysis of its syntactic aspect, it can be concluded that morphosyntactic-verb (MV) (2 (a-e)) above belongs to verb phrase (VP) in which there are morphosyntactic properties like honorific (Hn)/non-honorific (NHn) mood; first sub category of future tense (FUT 1 ), and the first singular person subject (marker).

13 It is difficult for the linguists familiar to Austronesia language to believe it, because it is uncommon. iii. Morphosyntactic Verb: First Sub Category of Past Tense (PAST $\left.T_{1}\right)$ Marker with the First Singular Person Subject $\{-i h\}$

Morphosyntactic properties constituting the first sub category of Past Tense $\left(\mathrm{PAST}_{1}\right)$ with the first singular person subject /an/ 'I', in ADYL is marked morphologically with \{$i h\}$. For further explanation about the morphosyntactic verb formation process with the first sub category of Past Tense $\left(\mathrm{PAST}_{1}\right)$, consider the morphological representation data in interlinear form. Consider also the morphosyntactic verb in bold italic in the morphological form in clauses/sentences (3(a-e)) below.

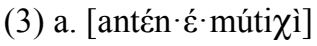

$$
\begin{array}{ll}
\text { ant - en e } m u(t)-r(i)-i h-i \\
1 \mathrm{~s}-\mathrm{TS} \text { wood } \mathrm{cut}-\mathrm{NHn}-\mathrm{PAST}_{1}-\mathrm{S}: 1 \mathrm{~s} \\
\mathrm{~S} 0 \mathrm{~V}
\end{array}
$$

'I have cut the tree'

$$
\begin{aligned}
& \text { b. [antćn } \cdot \dot{\varepsilon} \cdot \text { lisiri } \chi i] \\
& \text { ant - en e lisi }(k)-r(i)-i h-i \\
& \begin{array}{ccc}
\text { 1s }- \text { TS } & \text { wood } & \text { pull }-\mathrm{Hn}-\mathrm{PAST}_{1}-\mathrm{S}: 1 \mathrm{~s} \\
\hline \mathrm{S} & 0 & \mathrm{~V}
\end{array}
\end{aligned}
$$

'I have pulled the wood'

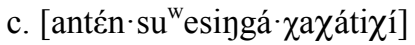

$$
\begin{aligned}
& \text { ant- en suesingga haha - } t(i)-i h \quad-i
\end{aligned}
$$

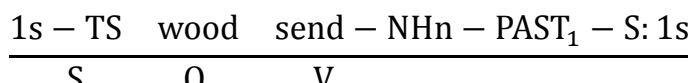

'I have sent the wood'

Each of morphosyntactic verbs in clauses (3 (a-c)) above is built on pre-categorical verb root $\sqrt{m u t}$ 'cut', and categorical

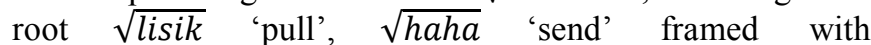
morphosyntactic property of first sub category of past tense $\left(\mathrm{PAST}_{1}\right)\{-i h\}$ concurrently with honorific $(\mathrm{Hn})\{-r-\}$ or nonHonorific $\{-t-\}$ morphemes filling in the space on its left, and the marker of first singular person subject on its right.

Viewed from semantic aspect, $\{-i h\}$ contains grammatical meaning (notion) 'work, action that has been done' corresponding to the verb to which it attaches. When $\{-i h\}$ exists along with honorific $\{-r(V)-\}$, nonhonorific $\{-t(V)-\}$, and $\{-i\} \rightarrow\{-r i h i\}$ or $\{-t i h i\}$ morphemes, it means 'the action or work that has been done; done by (grammatical) subject of the first person with polite $(\{-r i h i\})$ and or impolite $(\{-t i h i\})$ expression'.

Then to confirm the elaboration above, see the sequence of morphosyntactic verb (MV) formation process formulated diagrammatically below.




From the diagram above, it can be interpreted that the morphosyntactic verb existing in phonological exponent column belongs to root-verb-action sub classification $\left(\mathrm{V}_{\mathrm{t}}\right)$ of transitive verb $(\mathrm{V}$-tra) attached with the first category of past tense marker $\{-\mathrm{ih}\}$ with subject agreement of the first singular person $\{-i\}$. However, $\{-\mathrm{ti}\}$ or $\{-\mathrm{ri}\}$ as non-honorific/ honorific morpheme is inserted between $\{-i h\}$ and $\{\sqrt{v}\}$ or root, corresponding to the one to whom an individual is speaking. Corresponding to elaboration, the structure (str.) of morphosyntactic verb (MV) is represented below.

Str. MV-PAS $=\sqrt{ }+$ MOD:Hn/NHn + [(FUT 1$)(S . A g r: 1 s)]$

In addition, when the morphosyntactic verb (MV) above is elaborated syntactically, it can be concluded that the MV is classified into verb phrase (VP). It is also supported by morphosyntactic properties such as mood (MOD), first category of past tense (PAST 1 ), and subject agreement of the first singular personal pronoun (S:1s).

\section{Conclusion}

Conceptually, this study is a morphosyntactic research actually different from the theoretical concept of previous researchers in Indonesia. For that reason, the result of current research is certainly different from the result of two previous morphosyntactic studies. From the result of research, it can be found a number of morphosyntactic properties supporting the formation of morphosyntactic verb. Those morphosyntactic properties are summarized in the following conclusions.

1) Morphosyntactic property of mood includes: (i) honorific, (ii) non-honorific mood, (iii) desiderative and its subject agreement, (iv) imperative, and (iv) interrogative.

2) Morphosyntactic property of aspect includes: abituative, (ii), frequentative, (iii) durative.

3) Morphosyntactic property of tense includes: (i) present tense; (ii) first sub category of past tense (PAST 1 ), second sub category of past tense $\left(\mathrm{PAST}_{2}\right)$, third sub category of past tense ( $\mathrm{PAST}_{3}$ ), fourth sub category of past tense $\left(\mathrm{PAST}_{4}\right)$, first sub category of future tense $\left(\mathrm{FUT}_{1}\right)$, second sub category of future tense $\left(\mathrm{FUT}_{2}\right)$, third sub category of future tense $\left(\mathrm{FUT}_{3}\right)$, and fourth sub category of future tense $\left(\mathrm{FUT}_{4}\right)$ with transformation corresponding to the subject.

4) Morphosyntactic property of subject agreement, from the first singular personal pronoun (1s) to the third plural personal pronoun $(3 \mathrm{pl})$.

5) Morphosyntactic property of future tense $\left(\mathrm{FUT}_{1}, \mathrm{FUT}_{2}\right)$ and past tense $\left(\mathrm{PAST}_{1}, \mathrm{PAST}_{2}\right)$ intensifier.

6) Morphosyntactic property of object possessor marker
7) Morphosyntactic property of object case marker

8) Morphosyntactic property of causative verb marker

9) Morphosyntactic property of reciprocal diathesis marker: (i) balanced reciprocity, (ii) unbalanced reciprocity.

10)Morphosyntactic property of negation marker.

Out of ten items of morphosyntactic property above, four belong to property consistent with Lyons and Stumps' classification (items 1-4), while items 5-10 are found undertaking morphological process, in syntactic context, so that it can be categorized into new morphosyntactic property in morphosyntactic word, particularly in Indonesia.

\section{References}

[1] CashCash, Philips. 2004. Nez Perce Verb Morphology. University of Arizona. (http:// www.u. Arizona.edu.)

[2] Elson, Benjamin, and Velma Pickett. 1969. An Introduction to Morphology and Syntax. Santa Ana, California: Summer Institute of Linguistics.

[3] Foley, William A. (1986). The Papuan Languages of New Guinea. London: Cambridge University Press.

[4] Halle, M., and A. Marantz. 1993. "Distributed Morphology and the Pieces of Inflection", in K. Halle and S. Kayser (ed.) The View From Building 20: Essay in Linguistics in Honor of Sylvain Bromberger. MIT Press, Cambridge, MA, 111-176.

[5] Katamba, Francis. 1993. Morphology. London: The Macmillan Press.

[6] Lyons, J. 1977. Semantics. Cambridge: Cambridge University Press.

[7] Noyer, R. 1997. Features, Positions and Affixes in Autonomous Morphological Structure. New York: Garland.

[8] Radford, Andrew. 1997. Syntactic Theory and the Structure of English, a Minimalist Approach. Cambridge: Cambridge University Press.

[9] Roland, W. Scholz, and Olaf Tietje. 2002. Embedded Case Study Methods: Integrating Quantitative and Qualitative Knowledge.(accessed, on July 14, 2012, from: http://www.google.co.id/books?id)

[10] Samarin, W. 1988. IlmuBahasaLapangan. Yogyakarta: Kanisius Pub-lisher

[11] Silzer, Peter J. et.al. 1991. Index of Irian Jaya Languages. Collaboration Program ofCenderawasihUniversity and Summer Institute of Linguistics. Jayapura: SIL.

[12] Stump, Gregory T. 2001. "Inflection".InThe Handbook of Morphology. Edited by Andrew Spencer, and Arnold M. Zwicky.

[13] Malden, Massachusetts: Blackwell Publishers Inc. p. 13-43. 